\title{
Combining NHC bis-Phenolate Ligands with Oxophilic Metal Centers: A Powerful Approach for the Development of Robust and Highly Effective Organometallic Catalysts
}

\author{
Stéphane Bellemin-Laponnaz ${ }^{\star a b}$, Samuel Dagorne ${ }^{\star c}$, Ralf Dümpelmann ${ }^{\text {de }}$, and Pascal Steffanut ${ }^{\star d}$
}

Sandmeyer Award 2013

\begin{abstract}
The present paper describes an overview of a novel family of tridentate NHC pincer ligand in which two phenoxide moieties are directly connected to the nitrogen atoms of a central $\mathrm{N}$-heterocyclic carbene. It was envisioned that such a structure might be suitable for coordination to a variety of metal centers across the periodic table, including oxophilic metals. Various metal complexes bearing such ligand are indeed readily accessible in high yields via straightforward routes. Interestingly, a robust zirconium-NHC complex was found to polymerize rac-lactide in a highly controlled, living and stereoselective manner to afford heterotactic PLA.
\end{abstract}

Keywords: $\mathrm{N}$-Heterocyclic carbene $\cdot$ Organometallic catalysis $\cdot$ Ring-opening polymerization $\cdot$ Transition metal complexes

Stéphane Bellemin-Laponnaz studied chemistry at the Université Joseph Fourier (Grenoble) and the Université Louis Pasteur (Strasbourg). He obtained his doctorate in 1998 under the direction of Prof. John A. Osborn and Dr J. P. Le Ny working in the field of homogeneous catalysis. He then joined the group of Prof. Gregory C. Fu at the Massachusetts Institute of Technology (Cambridge, MA) as a post-doctoral fellow working on asymmetric reactions. In late 2000, he joined the group of Prof. Lutz H. Gade at the Université de Strasbourg as an associate researcher CNRS and moved in 2010 to the Institut de Physique et Chimie des Matériaux de Strasbourg as Directeur de recherche CNRS. His research interests are

${ }^{\star}$ Correspondence: Dr S. Bellemin-Laponnaz, ${ }^{\text {ab }}$ Dr S. Dagorne, ${ }^{\mathrm{C}}$ Dr P. Steffanut

Tel.: +33 388107166 (SBL); +33 368851542 (SD); +41614697082 (PS)

E-mail: bellemin@unistra.fr; dagorne@unistra.fr; Pascal.Steffanut@clariant.com

aIPCMS (Institut de Physique et Chimie des Matériaux de Strasbourg), CNRS-Université de Strasbourg, 23 rue du Loess BP 43, F-67034 Strasbourg, France bUniversity of Strasbourg Institute for Advanced Study (USIAS), 5 allée du Général Rouvillois,

F-67083 Strasbourg, France

Institut de chimie de Strasbourg, CNRS-Université de Strasbourg, 1 rue Blaise Pascal, F-67000 Strasbourg, France

${ }^{\mathrm{d}}$ Clariant International AG, Polymer Additives, MUT 904-242, Rothausstrasse 61, 4132 Muttenz, Switzerland

'Current address: Inolytix AG, Bahnhofstrasse 35 4334 Sisseln, Switzerland in the fields of organometallic chemistry, coordination chemistry and catalysis. He received the Bronze Medal of the CNRS in 2005, the Coordination Chemistry Division Prize of the French Chemical Society (SCF) in 2009, and is University of Strasbourg Institute for Advanced Studies 2013 Fellow.

Samuel Dagorne received his undergraduate degree in Chemistry at the
University of Rennes (France) in 1994. In 1995, he joined the group of Professor Richard F. Jordan at the University of Iowa (Iowa City, IA) and received his $\mathrm{PhD}$ degree in 1999 on the chemistry of chiral zirconocenes and group 13 compounds. In 1999, he became a member of the group of Professor Richard R. Schrock (Massachusetts Institute of Technology, Cambridge, MA) as a postdoctoral fellow

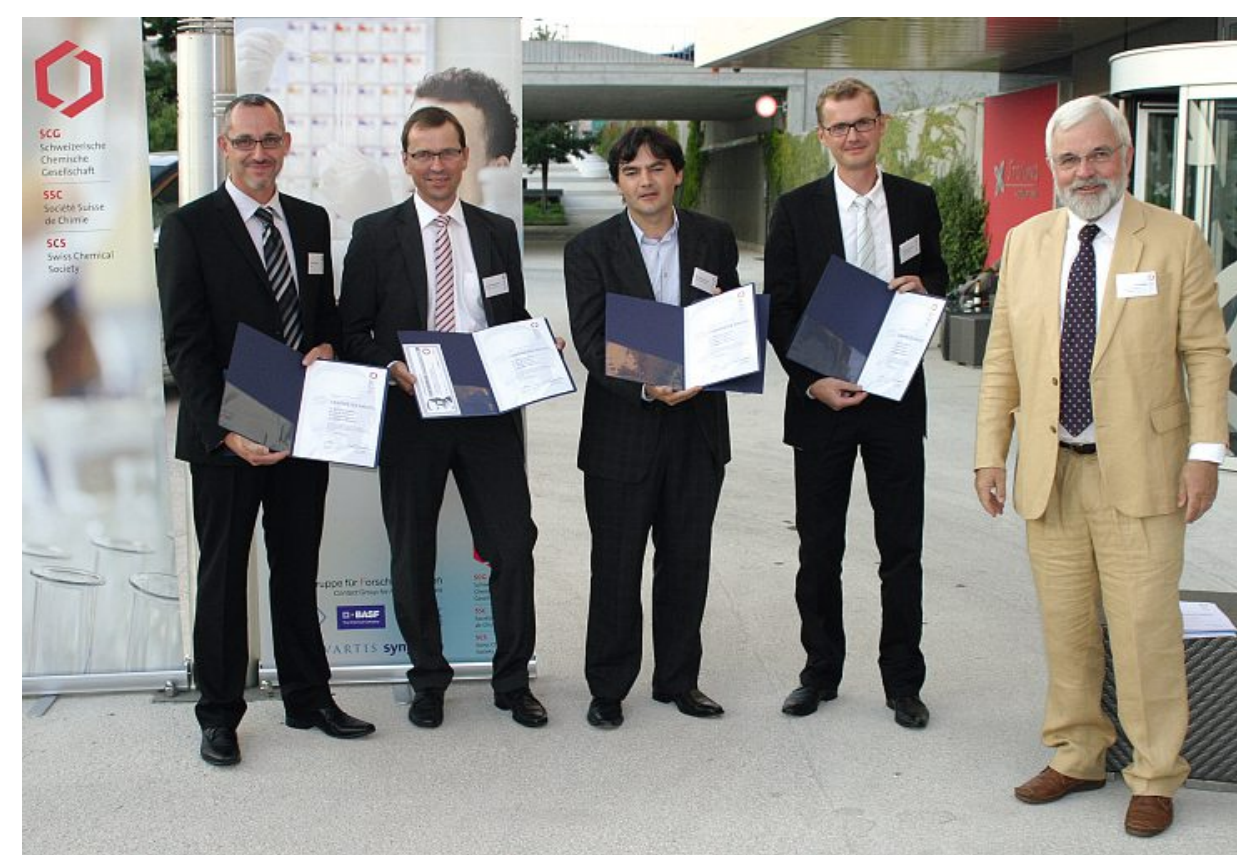

From left to right: PS, RD, SD, SBL, and Prof. Kündig, President of the Swiss Chemical Society. 
working on molybdenum alkylidene chemistry. Back in France, he joined the CNRS in 2000 as an associate researcher and is currently at the University of Strasbourg (France). His research interests mainly concern the synthesis, reactivity studies, and use in polymerization catalysis of organometallic complexes of oxophilic metals.

Early 2014, Ralf Dümpelmann founded his own company Inolytix AG and joined i-net innovation networks, the innovation support organization of the Northwestern cantons, managing the field of nanotechnology. Before, he worked over 13 years for Clariant in different $R \& D$ departments. In his last position there, he was director of the R\&D Center Formulation Technology. He was educated as chemical engineer at the ETH Zürich including a PhD in heterogeneous catalysis, followed by a postdoc position in Sydney, Australia. He worked five years as process engineer at Roche Vitamins, now DSM, and moved in 2000 to Clariant.

Pascal Steffanut currently heads the product management group for the business line polymer additives at Clariant. From 1998 to 2013, he was in charge of several R\&D projects in the field of pigments, optical recording dyes, textile chemicals, as project manager, and became R\&D group head for effect chemicals and intermediates in the same company. Pascal Steffanut studied chemistry at the universities of Toulon, Nice, Marseille and Strasbourg where he obtained his doctorate in 1996 under the direction of Prof. John A. Osborn working in the field of homogeneous catalysis for the hydrosilylation reaction. He then joined the group of Prof. A. Togni at ETH Zurich for a postdoctoral position. His current interests mainly concern the chemical production of new catalysts for polymerization processes, light and process stabilizers, UV absorbers and antistatics for the polymer industry.

\section{Introduction}

Over the past two decades, $\mathrm{N}$-heterocyclic carbenes (NHC) have attracted tremendous attention and are now considered as privileged ligands for coordination to metal complexes due to their exceptional ligating properties. ${ }^{[1]}$ Their bonding to late transition metals has been proven to yield kinetically inert, remarkably stable as well as air-/moisture-tolerant metal complexes, which obviously contributed to their development. NHC metal derivatives have found widespread applications in catalysis and more recently in medicinal chemistry (antimicrobial and cytotoxic agents) or material sciences (luminescence, liquid crystal, conducting polymer, etc.). ${ }^{[2]}$
During the mid-90s, the similarities between $N$-heterocyclic carbenes and phosphines regarding ligand properties were used as guidelines to study the coordination chemistry of the NHCs and the potential applications of the derived metal complexes. As a consequence, the use of NHC ligands for coordination to early-transition metals has been much less studied, which may explain the rather limited number of NHC early-transition metal complexes synthesized thus far.

Phosphine ligands display a soft base nature in the HSAB theory and therefore are better suited for late-transition metals. In contrast, $N$-heterocyclic carbenes have no necessary requirement for backbonding and, due to the strongly nucleophilic singlet lone pair, are suitable for a wider range of metals. However, to limit NHC dissociation in high-oxidation-state metals complexes, polydentate NHC-donor systems have been designed and synthesized to improve robustness of such coordination compounds. Potentially bidentate or tridentate systems, which include a neutral carbene surrounded by one or two oxygen or nitrogen-based anionic ligands appear to be promising candidates to afford stable early-transition metal complexes. ${ }^{[3]}$

In search of new tridentate pincer-type NHC dianionic ligand, we focused our attention on bis-phenolate-NHC chelating ligand as shown on Fig. 1. We envisioned that such a $\mathrm{L}, \mathrm{X}_{2}$-type ligand structure would be well suited for oxophilic highoxidation-state metals. In particular, (i) the use of phenolate arms would bring a rigid ligand platform and also avoid potential decomposition pathways of the ligand; (ii)

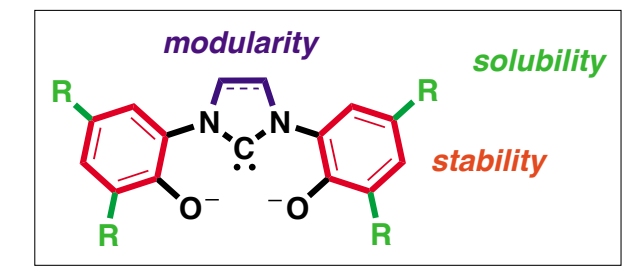

Fig. 1. General structure of the NHC bis-phenolate ligand.

\section{Ligand Precursor Synthesis}

We thus developed a straightforward synthesis of the corresponding azolium proligands with bulky substituents $(\mathrm{R}=$

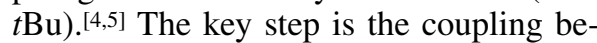
tween the 3,5-di-tert-butylcatechol and ethylene diamine to form N,N-bis(3,5-di-tertbutyl-2-hydroxyphenyl)-ethylenediamine (Scheme 1).[6] The originality of this approach is to take advantage of the ketoenol equilibrium in the starting catechol. The scope of application is illustrated by the selected examples depicted in Scheme 1. It is thus possible to access various azolium salts upon changing the nature of the starting diamine (including the use of chiral diamine precursors). For instance, benzimidazolium salts and/or cyclic formamidiniums with a fully saturated back-

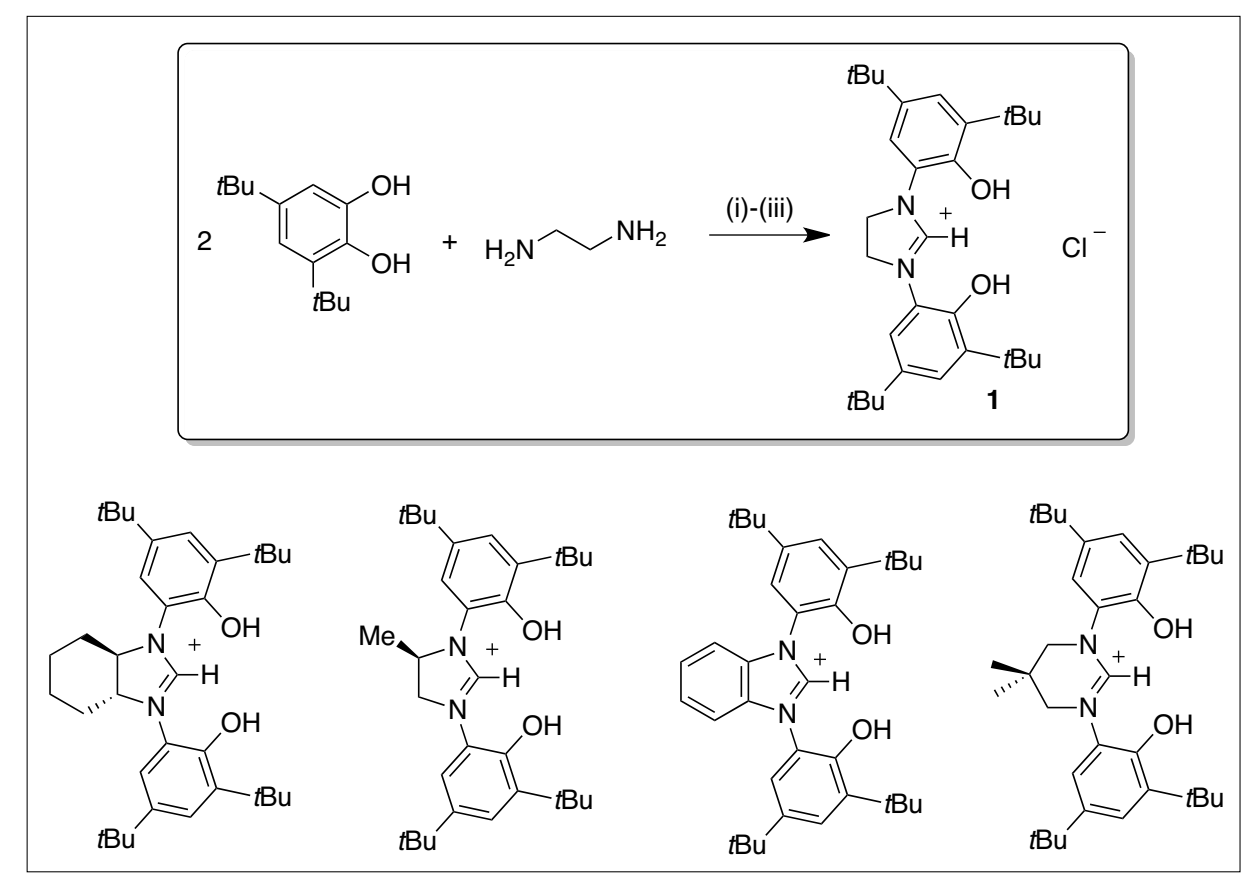

Scheme 1. Synthesis of symmetrical azolium chloride precursors starting from 3,5-di-tert butylcatechol. Conditions for 1: (i) acetonitrile, $\Delta$; (ii) $\mathrm{HCl}_{\text {aq. }}, \mathrm{MeOH}$ (iii) (EtO) ${ }_{3} \mathrm{CH}$. 
bone are easily accessible. Interestingly, such azolium chloride salts typically precipitate during the course of the reaction and may therefore be easily isolated via simple filtration with no further purification required.

\section{Synthesis of Metal NHC Complexes}

Several routes are known for the preparation of NHC complexes. [2] The most common approach involves the deprotonation of an azolium pro-ligand by an external strong base to generate the corresponding free carbene with a subsequent binding to a metal center. The use of an internal base is also a simple and practical method to implement since it may avoid the generation of air- and moisture-sensitive free carbenes. In that case, a ligand of the metal precursor will act as a base and in situ deprotonate the azolium salt with a direct complexation onto the metal center. We found that the alcohol elimination route involving the reaction of the imidazolium precursor 1 and one equivalent of a metal alkoxide precursor allows a straightforward access (and under mild conditions) to early transition metal complexes supported by NHC bis-phenolate ligands (Scheme 2).
Using the alcohol elimination approach, various NHC metal complexes could be readily produced in high yields and some representative examples are depicted in Fig. 2. The analytically pure vanadium (v) oxo complex 2 was prepared upon combining the corresponding azolium precursor with $\left(\mathrm{O}^{i} \mathrm{Pr}\right)_{3} \mathrm{~V}=\mathrm{O}$, followed by evaporation of the volatiles in vacuo. ${ }^{[7]}$ The titanium, zirconium and hafnium complexes 3-5 were obtained in the same way from $\mathrm{ClTi}(\mathrm{O} i \mathrm{Pr})_{3}, \mathrm{Zr}(\mathrm{O} i \mathrm{Pr})_{4}$ and $\mathrm{HfBn}_{4}$, respectively. ${ }^{[8-10]}$ It is noteworthy that the NHC bis-phenolate ligand provides a remarkable stability to the resulting metal chelates. Complexes $\mathbf{2}$ and $\mathbf{3}$ are robust and could be handled under air. Noticeably, such a ligand structure can also readily coordinate mid- and late transition metals (with the species 6 and 7) or group 13 metal derivatives (8) (Fig. 2). ${ }^{77,11,12]}$

Several molecular structures of these NHC metal complexes were determined by $\mathrm{X}$-ray crystallography, which confirmed the effective chelation of the NHC bisphenolate moiety to the metal center. For example, as illustrated in Fig. 3, the zirconium atom in complex $\mathbf{4}$ adopts a distorted octahedral geometry as a result of the mer coordination of the ligand.
NHC. $\mathrm{HCl}+\mathrm{M}(\mathrm{OR}) \mathrm{L}_{\mathrm{n}} \longrightarrow[\mathrm{NHC}] \mathrm{ML}_{\mathrm{n}}-\mathrm{Cl}+\mathrm{R}-\mathrm{OH}$

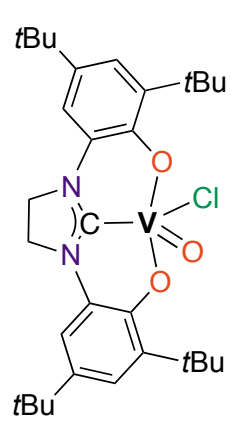

2

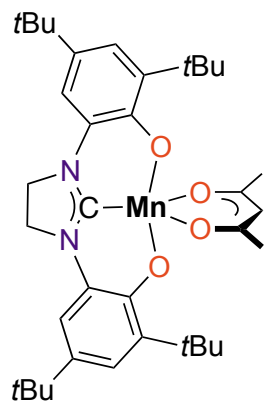

6

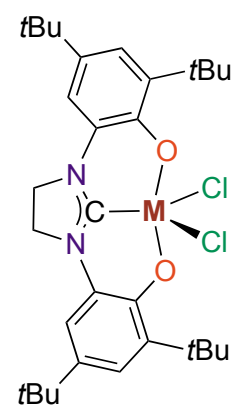

3

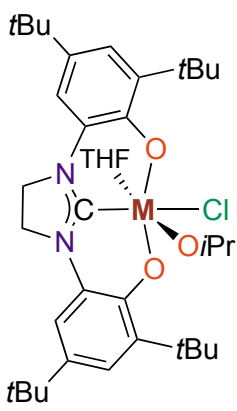

$\mathbf{M}=\mathrm{Ti}, \mathrm{Zr}$ or $\mathrm{Hf}$
Scheme 2. Formation of [NHC]M complexes.

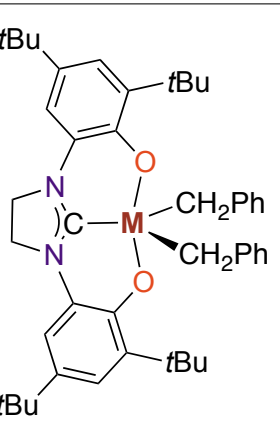

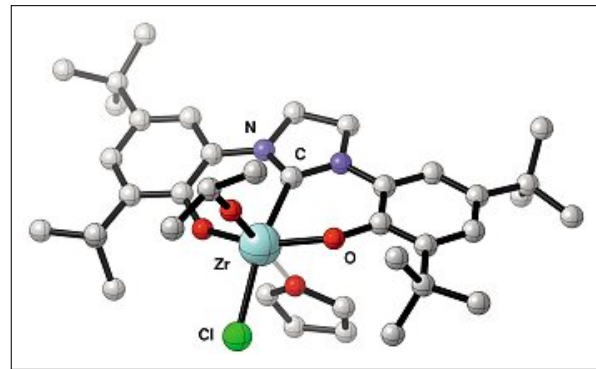

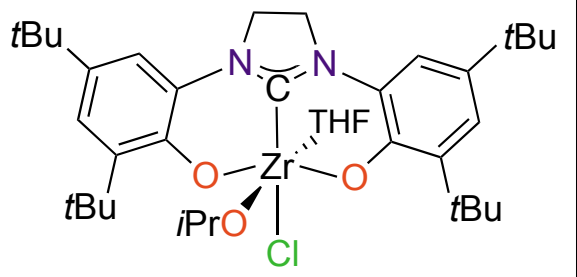

Fig. 3. Molecular structure of the zirconium complex 4

\section{Application to the Living and Stereoselective Polymerization of Cyclic Esters/Carbonates}

Biodegradable polyesters and polycarbonates, such as polylactide, polycaprolactone or poly-trimethylene carbonate are of current interest due their various applications in numerous domains including their use in the biomedical and pharmaceutical fields. The ring-opening polymerization (ROP) of cyclic esters or carbonates constitutes the most efficient approach to access well-defined polyesters or polycarbonates in a controlled manner. ${ }^{[13]}$ Typically, the ring-opening process is driven thermodynamically by release of the ring strain and the process may be finely controlled to access precise molecular weights, narrow molecular weight distribution and also, when appropriate, regio- and stereoselectivity. All these parameters are of primary importance since, in general, a low polydispersity index with a high tacticity level are prerequisites for such biodegradable polymers to be commercialized.

Commercial polylactide is currently produced industrially by ROP of L-lactide using tin(II) octanoate.[14] Increasing efforts are being devoted towards the development of single-site metal-based initiators to access polymers under the most efficient conditions. Discrete ligand-supported alkoxide complexes of oxophilic metals $(\mathrm{Mg}$, $\mathrm{Ca}, \mathrm{Zn}, \mathrm{Al}$ or rare-earth metals) are wellestablished initiators for the ROP of lactide.[13] Comparatively, group 4 analogues have been less studied prompting us to investigate the potential utility of group 4 metal NHC species in this field and, in particular, to study the added value that the carbene ligand might provide in this area.

It was thus found that a $\mathrm{Ti}$ monoalkoxide chloro derivative of type $\mathbf{4}$ polymerizes rac-lactide in a controlled manner

Fig. 2. Some representative examples of metal complexes bearing a NHC bis-phenolate ligand of type 1. 
(polydiversity index (pdi) <1.1) albeit with no stereoselectivity, thus producing atactic polylactide (PLA) (89\% conversion to PLA of 100 equiv. of rac-lactide, toluene, $\left.15 \mathrm{~h}, 90^{\circ} \mathrm{C}\right) .{ }^{[8]}$ Surprisingly, going from titanium to zirconium led to highly active systems under mild conditions. [9] The $\mathrm{Zr}$ iso-propoxy chloro derivative of $\mathbf{4}$ polymerizes $r a c$-lactide at room temperature and, most importantly, in a controlled and highly stereoselective manner to yield narrowly disperse and highly heterotactic PLA (pdi $<1.1$ and $P_{\mathrm{r}}>0.95$, Table 1$) .{ }^{[15]}$ In addition, the direct use of commercial rac-lactide without further purification has little effect on the activity and selectivity (commercial lactide typically contains protic impurities such as lactic acid). It is worth highlighting that the prepared polymers were isolated as semicrystalline materials due to the high level of the heterotacticity of the produced PLA.

The good activity and selectivity of the Zr-NHC complex along with its apparent robustness encouraged further investigations of this system to develop its attractive features for possible industrial application (i.e. simple and cost-effective catalyst synthesis, low catalyst cost and low trace of residual metal in the final product). In the presence of various alcohols, the $\mathrm{Zr}$ NHC complex 4 polymerizes rac-lactide in a controlled and immortal manner to afford narrowly dispersed corresponding PLA. Scheme 3 displays some representative examples. Under these conditions, it is thus possible to generate well-defined and tailor-made block copolymers such as amphiphilic PEG-PLA, PDMS-PLA or polymers with specific liquid crystal properties (i.e. PLA with a cholesteryl end group).

Finally, the excellent polymerization performances of the Zr-NHC initiator 4 were further exploited for the synthesis of co-polymeric materials. Indeed, block copolymers, such as PTMC-PLA [PTMC = poly(trimethylene carbonate)], hold interest in many applications including biomaterials. ${ }^{[16]}$ In particular, the micro-structure of block copolymers may potentially be controlled and fine tuned, which in turn impacts the properties of biomaterials. Such properties (biological, physical, mechanical, degradation...) can be controlled by modulating the nature of the block polymers. Also, the tacticity of the PLA fragment is obviously a parameter that will affect the final properties of the material. The Zr-NHC complex 4 was found to readily polymerize $\varepsilon$-caprolactone (CPL), glycolide (GA) or 1,3-trimethylene carbonate (TMC):[17] it is thus possible to generate well-defined heterotactic PLA-PCPL, PLA-PGA or PLA-PTMC (Fig. 4). These block copolymers were simply prepared by the initial ring-opening polymerization of $\varepsilon$-caprolactone, glycolide or 1,3-tri-

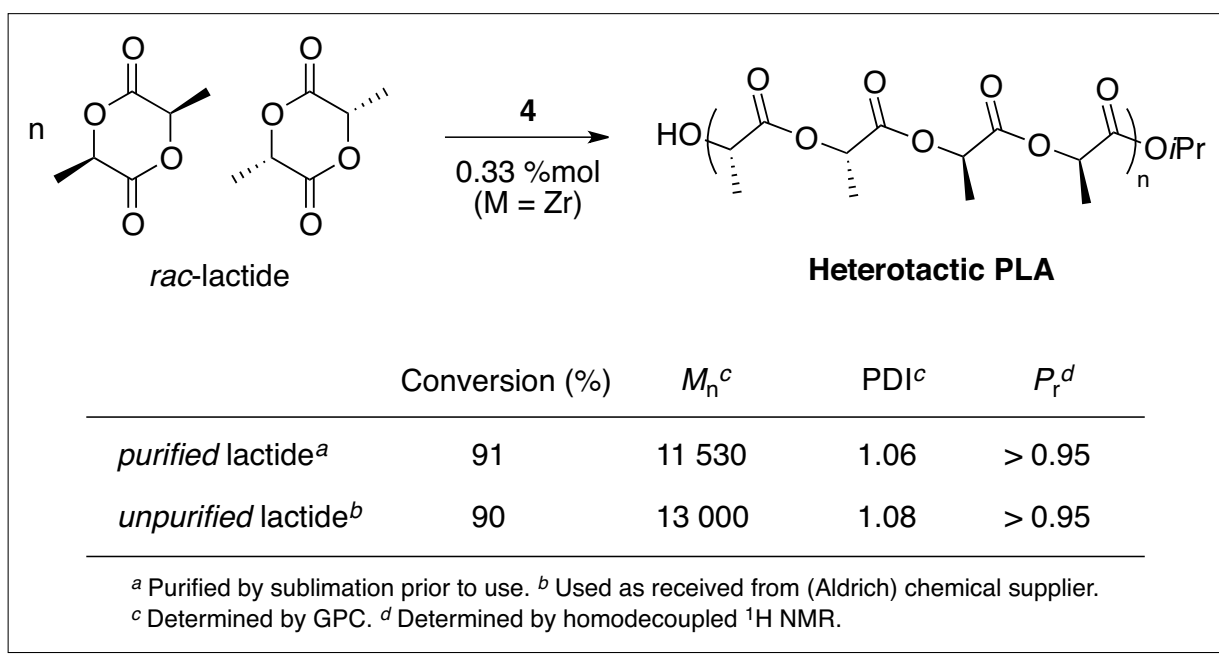

Table 1. Ring-opening of rac-lactide initiated by the $\mathrm{Zr}$ species $\mathbf{4}$ (Conditions: $\mathrm{CH}_{2} \mathrm{Cl}_{2}$, [lactide] $=1 \mathrm{M}$, room temperature).

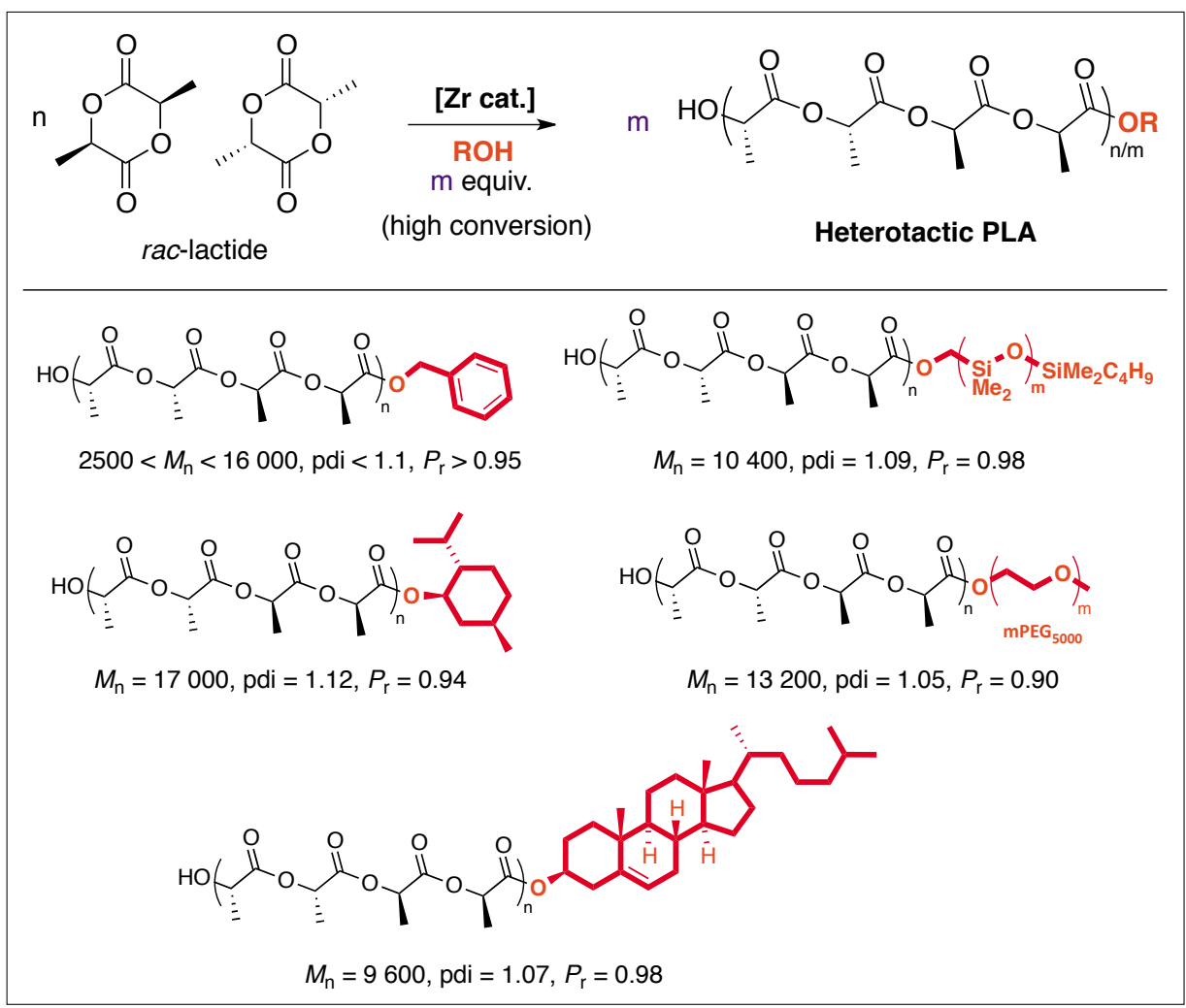

Scheme 3. Ring-opening of rac-lactide initiated by the Zr species $\mathbf{4}$ under catalytic conditions. Selected examples of the produced polymers.

methylene carbonate and the subsequent ROP of rac-lactide to yield well-defined, molecular-weight controlled and highly stereoregular heterotactic materials.

\section{Conclusion}

The tridentate NHC bis-phenolate ligand appears to be a quite versatile and robust ligand for coordination chemistry and its applications. The synthetic route of the ligand precursors is characterized by its ready synthesis through a three high-yield step procedure and facile purification. The preparation of the corresponding NHC car- bene metal complexes is straightforward and high yielding. In the case of oxophilic metals, the alcohol elimination pathway involving the direct reaction of the azolium precursor with a metal alkoxide was found to lead to the corresponding complexes in quantitative yield and no further purification may be required.

As envisioned, such a ligand structure is suitable for coordination to a variety of metal centers across the periodic table from group 4 transition metals to group 13 metals, usually giving stable and highly robust compounds.

The Zr-based NHC complexes efficiently mediate the controlled stereo- 


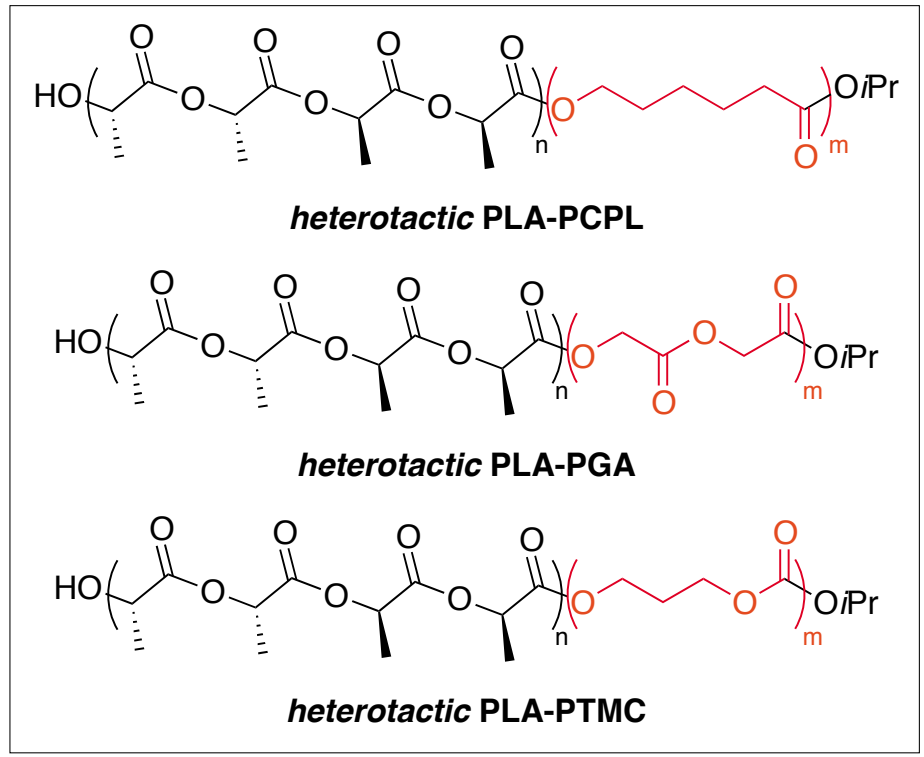

Fig. 4. Examples of the molecular structure of block copolymers obtained using $\mathrm{NHC}-\mathrm{Zr} 4$ as initiator.

selective ring-opening polymerization of rac-lactide to produce highly chain-length controlled and heterotactic PLA at room temperature. Remarkably, these high levels of polymerization control and stereoselectivity are unaltered under catalytic conditions, i.e. in the presence of an excess of alcohol acting as a chain transfer agent. These initiators also allowed access to well-defined and highly heterotactic block bio-copolymers.

\section{Acknowledgment}

This work was supported by the CNRS (France), the University of Strasbourg (France) and Clariant International AG. We gratefully acknowledge all of our collaborators whose names appear in the references cited.

Received: June 30, 2014

[1] a) S. P. Nolan, 'N-Heterocyclic Carbenes in Synthesis', Wiley-VCH, Weinheim, 2006; b) F. Glorius, 'N-Heterocyclic Carbenes in Transition Metal Catalysis', Springer-Verlag, Berlin, 2007; c) S. Díez-González 'N-Heterocyclic Carbenes, From Laboratories Curiosities to Efficient Synthetic Tools', RSC Catalysis Series, RSC Publishing, Cambridge, 2001.
[2] Selected reviews: a) W. A. Herrmann, C Köcher, Angew. Chem. Int. Ed. 1997, 36, 2162; b) A. J. III Arduengo, Acc. Chem. Res. 1999, 32, 913; c) D. Bourissou, O. Guerret, F. Gabbaï, G. Bertrand, Chem. Rev. 2000, 100, 39; d) V. César, S. Bellemin-Laponnaz, L. H. Gade, Chem. Soc. Rev. 2004, 33, 619; e) L. H. Gade, S. BelleminLaponnaz, Coord. Chem. Rev. 2007, 251, 718; f) P. L. Arnold, S. Pearson, Coord. Chem. Rev. 2007, 251, 596; g) D. Pugh, A. A. Danopoulos, Coord. Chem. Rev. 2007, 251, 610; h) S. DíezGonzález, S. P. Nolan, Coord. Chem. Rev. 2007, 251, 874; i) F. E. Hahn, C. J. Mareike, Angew. Chem. Int. Ed. 2008, 47, 3122; j) S. DíezGonzález, N. Marion, S. P. Nolan, Chem. Rev. 2009, 109, 3612; k) O. Schuster, L. Yang, H. G. Raubenheimer, M. Albrecht, Chem. Rev. 2009, 109, 3445; 1) M. Poyatos, J. A. Mata, E. Peris, Chem. Rev. 2009, 109, 3677; m) L. Mercs, M. Albrecht, Chem. Soc. Rev. 2010, 39, 1903; n) C. Fliedel, G. Schnee, T. Avilés, S. Dagorne, Coord. Chem. Rev. 2014, 275, 63.

[3] S. T. Liddle, I. S. Edworthy, P. L. Arnold, Chem. Soc. Rev. 2007, 36, 1732; b) O. Kühl, Chem. Soc. Rev. 2007, 36, 792.

[4] S. Bellemin-Laponnaz, S. Dagorne, C. Romain, S. Steffanut, WO 2012076140 (A1).

[5] For a review on the synthesis of NHC precursors, see: L. Benhamou, E. Chardon, G. Lavigne, S. Bellemin-Laponnaz, V. César, Chem. Rev. 2011, 111, 2705.

[6] K.S. Min, T. Weyermuller, E. Bothe, K. Wieghardt, Inorg. Chem. 2004, 43, 2922.
[7] S. Bellemin-Laponnaz, R. Welter, L. Brelot, S. Dagorne, J. Organomet. Chem. 2009, 694, 604.

[8] a) C. Romain, L. Brelot, S. Bellemin-Laponnaz, S. Dagorne, Organometallics 2010, 29, 1191; b) C. Romain, S. Choua, J. P. Collin, M. Heinrich, C. Bailly, L. Karmazin-Brelot, S. BelleminLaponnaz, S. Dagorne, Inorg. Chem. 2014, 53, 7371.

[9] a) C. Romain, B. Heinrich, S. BelleminLaponnaz, S. Dagorne, Chem. Commun. 2012, 2213; b) C. Romain, K. Miqueu, J. M. Sotiropoulos, S. Bellemin-Laponnaz, S. Dagorne, Angew. Chem. Int. Ed. 2010, 49, 2198.

[10] S. Dagorne, S. Bellemin-Laponnaz, C. Romain, Organometallics 2013, 32, 2736.

[11] E. Borré, G. Dahm, A. Aliprandi, M. Mauro, S. Dagorne, S. Bellemin-Laponnaz, submitted.

[12] C. Romain, C. Fliedel, S. Bellemin-Laponnaz, S. Dagorne, Organometallics 2014, DOI: 10.1021/om5004557.

[13] Selected reviews: a) S. Dagorne, M. Normand, E. Kirillov, J.-F. Carpentier, Coord. Chem. Rev. 2013, 257, 1869; b) A. Sauer, A. Kapelski, C. Fliedel, S. Dagorne, M. Kol, J. Okuda, Dalton Trans. 2013, 42, 9007; c) A. Arbaoui, C. Redshaw, Polym. Chem. 2010, 1, 801; d) R. H. Platel, L. M. Hodgson, C. K. Williams, Polym. Rev. 2008, 48, 11; e) J. Wu, T.-L. Yu, C.-T. Chen, C.-C. Lin, Coord. Chem. Rev. 2006, 250, 602; f) O. Dechy-Cabaret, B. Martin-Vaca, D. Bourissou, Chem. Rev. 2004, 104, 6147; g) B. J. O'Keefe, M. A. Hillmyer, W. B. Tolman, J. Chem. Soc. Dalton Trans. 2001, 2215.

[14] a) P. R. Gruber, E. S. Hall, J. J. Kolstad, M. L. Iwen, R. D. Benson, R. L. Borschadt, US Patent, 5,258,488, 1993, Cargill Inc.; b) P. R. Gruber, J. J. Kolstad, E. S. Hall, C. R. S. Eichen, C. M. Ryan, US Patent, 6,143,863, 2000, Cargill Inc.

[15] $P_{r}$ is defined as the probability of racemic linkage.

[16] B. Bhushan, S. R. Schricker, J. Biomed. Mater. Res. Part A 2014, 102A, 2467.

[17] Noticeably, the ROP of TMC for the production of chain-length controlled and narrow disperse PTMC material remains rare. See, for instance: a) F. Hild, L. Brelot, S. Dagorne, Organometallics 2011, 30, 5457; b) F. Hild, N. Neehaul, F. Bier, M. Wirsum, C. Gourlaouen, S. Dagorne, Organometallics 2013, 32, 587. 